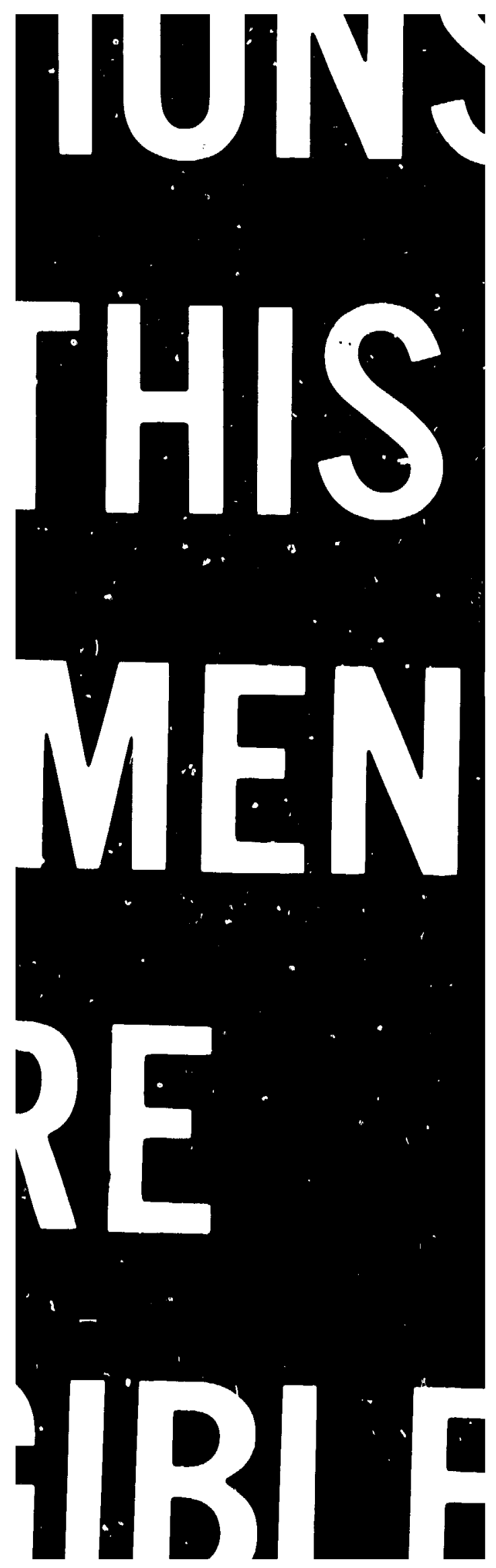


LA.UR-81-2820

\section{MASTER}

AUTmOn(S) Barry L. Barthell and David V. Duchane

suemitrio to 28th National American Vacuum Soclety Symposium, Anaheim, CA, November 1981

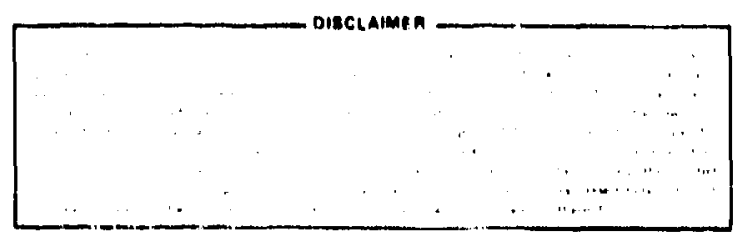

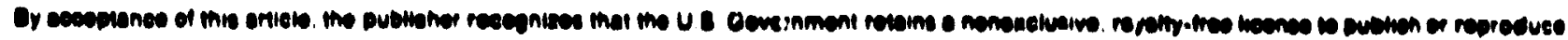

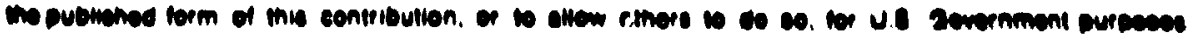

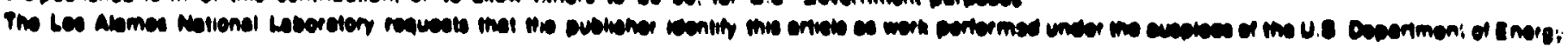

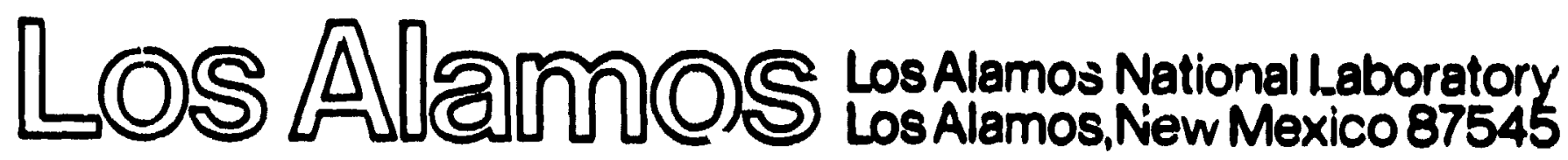




\title{
VACUUM DEPOSITION OF HIGH QUALITY \\ METAL FILMS ON POROUS SUBSTRATES
}

\author{
Barry L. Barthe11, David V. Duchane \\ Los Alamos Nationa] Laboratory
}

Abstract

A comfosite mandrel has been developed consisting of a core of low deusity polymethylpentene foam overcoated with a thin layer of film forming polymer. The surface tension and viscosity of the coating solution arc important parameters in obtaining a polymer film which forms a continuous, smooth skin over the corc without penetrating into the foam matrix. Water soluble film formers with surface tensions in the range of 45 dynes'sm and ininimum viscositics of a lew hundred centipoises have been found most satisfactory for coating polymethylpentene foain.

By means of this technique, continuous polymer fllms with thicknesses of 10-20 $\mu$ in have been formed on the surface of machined polymethylpentene foam blanks. Aluminum has been vaeuun deposfted onlo these compostte mandrels te produce metal films; which appear smooth and generally defect free cen $n$ 10,000 t Imes magntelcatlen. 


\section{INTRODUCTION}

The substrate plays a key role in the fabrication of thin metal films by vacuum deposition, since any defects or irregularities in the surface of the substrate tend to be reproduced in the film. ${ }^{1}$ Further, if a freestanding film is to be produced, the substrate must be removed after deposition of the film material. This can readily be accomplished with parting agents when films are formed as flat sheets of moderate size, but when they are to be made with closed shapes such as cylinders or spheres, removal of the mandrel is much more difficult. In these cases mandrels are generally removed by leaching processes which may be very time consuming. Mechanical agitation is ofien enployed in the leaching process, but this poses 2 sisk to the integrity of the thin filu. In addition, the leaching fluid itself mus: be carefully chosen. Metal mandrels require leachants which may be corrosive, difficult to handle, and prone to atiact the thin film itscle if paraneters such as teilperature and pli are not carcfully controlled. Polymeric mandrel materials, while soluble in organic livuids which pose no danger to the deposited lietal falm, are usually slow to disurive and often swell noticcably prior to becoming completely cluid. Such swolling can destroy the deposited sholl.

The ultinate geal of the work reported herein is the development of a composite mandrel consisting of a core of low density, open cell, polymeric foam, overconted with a thin 
layer of a smooth polymer $f \leq l m$. Such a mandrel would have a microscopically smooth surface, an extremely high surface to mass ratio, and an effective void volume approaching $95 \%$. These qualities would largely obviate many of the problems associated with the fabrication of metal-walled fusion targets. The smooth surface would permit the deposition of metallic films of good strength and uniformity. Leaching would be facilitated by the high surface il mass ratio, or could possibly be eliminated entirely by simply filling the voids with fuel and leaving the foam core as a permanent structural support .

Coating of polymer foams has been practiced in the plastics industry for a number of years, but microscopirally smooth finlshes have not generally been among the goals of coating processics." juch surface smoothness as has been achicved often involves the use of fillers and relatively thick coatings. ${ }^{2,3}$

1t. has boen the primary ohjuct of this work to develop coating unterials which will form cont lnuesus thin filins on the surface of a low density, open cell foam without penetrating significantly tnto the body of the form structure. As wlll be: Hhown below, the surface tension ancl viscosity of the coatlig selution are fmportant factors in the success of this techI. licue. 


\section{EXPERIMENTAL}

The polymer foam used in this work was obtained by a process recently developed at the Los Alamos National Laboratory. ${ }^{4}$ It consists of polymethylpentene, and is originally produced as a filled material. For these experiments, the filled foam was first machined into hollow cylinders $23-\mathrm{mm}$ long and $13 \mathrm{~mm}$ in diameter. The filler was then leached out to yield a inandrel core of low density (about $0.05 \mathrm{~g} / \mathrm{cm}^{3}$ ), open cell, pure hydrocarbon material. At this stage of the process, the surface of the foam was macroscopically smooth but microscopically rough and porous with an average cell sice of about $25 \mu \mathrm{m}$.

In each trial the coating solution was applied to the surface of the foam by lowering the cure into the coating liquid on a rod extended through its center until it was totally immersed, and then withdrawing it at a constant rate of about $15 \mathrm{~mm} / \mathrm{min}$. The excess coat ing fluid was allowed lo drain from the surface while the sample was suspended vertically.

The samples were dryed in a laminar air flow hood to minimi\%c dust contamination. After drying, each sample was inspected visually and by scanning elcetron microscopy (SEM). Aluninum was vapor deposited onto sanples of foan coated with the most promising formulations, and the aluminized surfaces again cxanined by SBM. 
The coating solutions were prepared by dissolving polymers known to be good film formers in water or methanol. The materials and concentrations were chosen to give solutions with a wide range of surface tensions and viscosities. Each solution was colored red to make visual observation of its behavior during the coating process easier to observe. Tests showed that the dye (Eosin $B$ at $0.1 \%$ concentration) did not affect the surface tension or viscosity of the solutions.

Surfiace tension measurements were made by the du Nouy ring method with a Fisher Model 20 Surface Tensiometer. Viscosities were determined with a Brookfield Model IVT Viscometer.

RF.SIII.TS AND DISCUSSIONS

The jimportant properties of the film forming solutions used in this work are sunmarized in lable I. These sojutions have surface tensions ranging from a high value only 8 dynes $/ \mathrm{cm}$ below that of pure water down to values typical of many common organic solvents. 5 The lowest yiscosity material has a consistency similar to that of water while the higlest viscosity solution is about as thick as table syrup. The nuincrical. desigrations given in Table 1 will be used when tefarring to specific solutions in the discussion which follows.

Figure la shows polymethylpentene cylinders after coating with solution Noss. 1, 3, and 5. These have similar viscosities 
but surface tensions of 68,45 , and 27 dynes/cm respectively. It is apparert that the high surface tension solution did not thoroughly wet the surface of the foam. As a result only blotches of film were formed on the surface of the cylinder. The liquid of intermediate surface tension formed a smooth coating on the surfase of the foam but did not appear to penetrate into the body of the cylinder. As indicated by the depth and uniformity of the color of the third cylinder, the low surface tension solution soaked into the pores of the foam, and in effect, filled it. Since all the coating solutions were of about the same color intensity, the differences in color of the coated cylinders provide a good qualitative guide to the behavior of the coating solutions.

Figures 1b-d show SEM's of the surfaces of the three cylinders pictured in Fig. 1a. This microscopic vicw reveals that even the portion of the cylinder treated with solution No. 1 (Fig. Ib) which did accept a coating had a surface marked by swirls and craters. The surface of the foam coated with solution No. 3 (Fig. 1c), while not absolutely smooth, shows only minor surface irregularities. Rather than being pits or pointed projections, these irregularities are in the form of troughs or mounds with gently sloping walls. It is known that a high angle of incidence may be important to obtaining high strength metal films by vapor deposition. ${ }^{6}$ Gent.le undulatiors do not pose the problem that pits and points do in this regard. 
The surface coated with solution No. 5 (Fig. 1d) is seen to be cellular in nature, indicating no significant bridging of the pores of the polymethylpentene foam.

The importance of surface tension in this coating process is further illustrated in Fig. 2. Here SEM's of the surfaces of foan cylinders coated with solutions No. 4 (Fig. 2a) and No. 6 (Fig. 2b) are shown. Both surfaces were coated with the same type of polymer (although the molecular weight of the polymer was somewhat higher for solution Nọ. 6), but from different solvents. Again, the solution having a surface tension of intermediate value is seen to produce a relatively smooth surface, while the low surface tension liquid, even th'sugh higher in viscosity, does not adequately bridge the pore:s in the foan.

The quality of the surface coating on the polymethylpentene foam is also somewhat dependent upon the viscosity of the coating solution. This i.s shown in Fig. 3 which is an SEM of the surface of a foam cylinder coated with solution No. 2 . While this was the same polymer used to coat the foam shown in Fig. 1b, and the superficial appearance of the cylinder after coating was similar, the lower viscosity of this solution led to excessive runoff and incomplete briclging of some of the foam pores. The fact that a majority of the cells were closed by this coating indicates that the concentration of the polymer was high enough to permit flli. formation to take place. 
The chicknesses of the two polymer films which produced continuous, smooth surfaces on the polynethylpentene foam (solutions No. 3 and 4) can be estimated from SEM's of cross sections of foam cylinders coated with these solutions. These SEM's are shown in Fig. 4. In both cases, the outer continuous

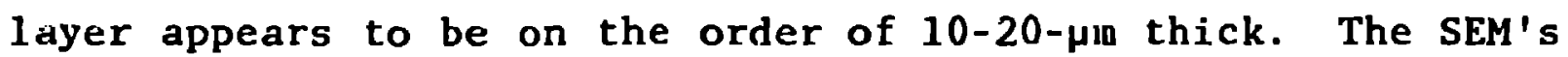
also indicate that these polymer coatings are confined essentially to the surfaces of the foam cylinders.

Finally, Fig. 5 shows an SEM of the surface of a 5- $\mu \mathrm{m}-$ thick aluminum/aluminum oxide film vacuum deposited onto a polymer coated polymethylpentenc foam sample using the pulsed gas process. 7 In this case, the polyner coating was applied by dipping in solution No. 2, but the sample was a flat disk rather than a cylincler. This SEM illustrates the extremely smooth aluminum films which may be obtained by this technique.

CONCLUSIONS

A composite mandrel composed of a core of polymer foam overcoated with a thin, smooth, polymer film can be used as a substrate for the vacuun deposition of high quality metal filasi. The surface tension and viscosity of the coating solution are key propertics in the fabrication of such a composite mandrel. For hydrocarbon foams such as polymethylpentene, the coating solution should have a surface tension in the range of 45 dynes/cm, and certainly greater than 30 dynes/cm. Since many common organic liquids have surface tensions lower than 
this value, ${ }^{5}$ water-based film forming solutions would seem to be particularly suited for coating hydrocarbon foams.

The viscosity of the coating sulution must be above a certain minimum to ensure adequate bridging of the foam pores. For polymethylpentene with an average cell size of $25 \mu \mathrm{m}$ this minimum has been found to be a few hundred centipoises. Higher viscosities might be expected to lead to thicker polymer coatings. At extremely high viscosities it is likely that the material would stiffen before leveling took place and the desired smooth surface would not be realized.

ACKNOWLEDGMENTS

The authors would like to thank Dr. Ainslie T. Young for supplying and leaching the polymethylpentene foam used in this work and David Murphy for machining this unique material to close tolerances. The work of Chuck Javorsky in preparing the SEM's used in this paper is also gratefully acknowledged. 


\section{REFERENCES}

1. L. Máissel and R. Gları, Editors, Handbook of Thin Film Technology (McGraw-Hill, New York, 1970)

2. C. D. Storm, Plastics Engineering, 36, (8), 36 (1980).

3. Anonymous, Plastics Technology 24, (12), 117 (1978).

4. A. T. Young, D. K. Moreno, and R. G. Marsters, Paper No. VFWM-15, American Vacuum Society, $2 \dot{8}$ th National Symposium (1981).

5. R. C. Weast, Ed, Handbook of Chellistry and Physics, 52nd Edition (Chen.ical Rubber Co., Cleveland, Ohio, 1971).

6. R. W. Springer and D. S. Catlett, Technical Digest of Conference on Inertial Confinement Fusion (1980).

7. R. W. Springer and D. S. Catlett, Thin Solid Filıs, 54, 197 (1978). 


\section{FIGURE CAPTIONS}

Fig. 1 a. Photograph of foam cylinders coated with high, medium, and low ( 1 to $r$ ) surface tension film formers. b-d. SEM's of the surfaces of these cylinders. Note the superiority of the surface coated with the medium surface tension film former.

Fig. 2 SEM's of surfuces of foam cylinders coated with hyclroxypropylcellulose (IIPC) from intermediale and low surface tenston solutions.

Fig. 3 SFM of surface of foall coated with low viscosity polyvinyl alcohol solution.

Fig. l, SkM's of cross sectlons; of foum cyliulers conted with good film foriners. Note the continuous fillil at the sur-[ace of casch cylinder.

lifi. 5 SEM of $\Lambda \mathrm{L} / \mathrm{Al}_{2} \mathrm{O}_{3}$ Laminale vasuull deposiled ol foam/ film composilte mindierl. 
TABLE I. Important Properti $\underline{\text { s of Film Forming Solutions }}$

\begin{tabular}{|c|c|c|c|c|c|}
\hline $\begin{array}{l}\text { Solution } \\
\text { No. } \\
\end{array}$ & $\begin{array}{c}\text { Fild Forming } \\
\text { Polymer } \\
\end{array}$ & Solvent & $\begin{array}{c}\text { Polymer } \\
\text { Concentzation (\%) }\end{array}$ & $\begin{array}{c}\text { Surface } \\
\text { Tention(dynes } / \mathrm{cm} \text { ) }\end{array}$ & $\begin{array}{l}\text { Viscosity } \\
\text { (cps) } \\
\end{array}$ \\
\hline 1 & $C Y C-7 L^{(a)}$ & bater & 5 & 68 & 180 \\
\hline 2 & $\begin{array}{l}\text { Polyyinyl Alcohol, } \\
88 \% \text { hydrolyzed }\end{array}$ & hater & 10 & 45 & 30 \\
\hline 3 & $\begin{array}{l}\text { Polyvinyl Alcohol, } \\
\text { 88: hydrolyzed }\end{array}$ & hater & 20 & 45 & 480 \\
\hline 4 & Klucel $E^{(b)}$ & Water & 15 & 45 & 1300 \\
\hline 5 & Klucel $E^{(b)}$ & Methano! & 15 & 27 & 270 \\
\hline 6 & Klucel $\mathrm{J}^{(\mathrm{b})}$ & Methanol & 15 & 28 & 3000 \\
\hline
\end{tabular}

a CMC is a trademark of Hercules Inc. for Sodium Carboxymethylcellulose.

b Rlucel is a trademark of Hercules Inc. for Hydroxypropylcellulose. 


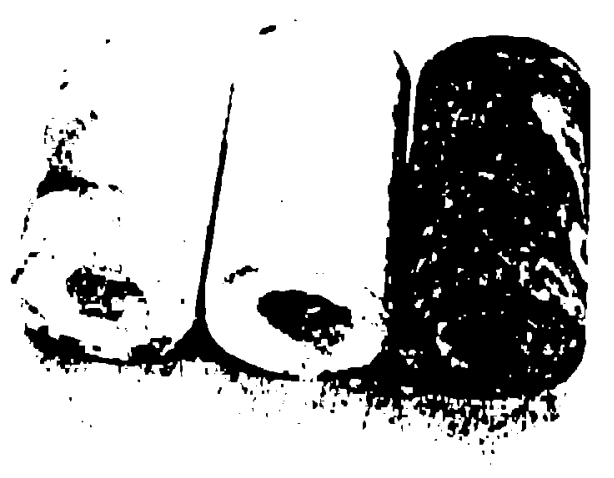

0

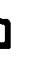

.

C

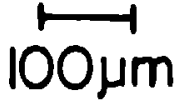

45 dynes/cm

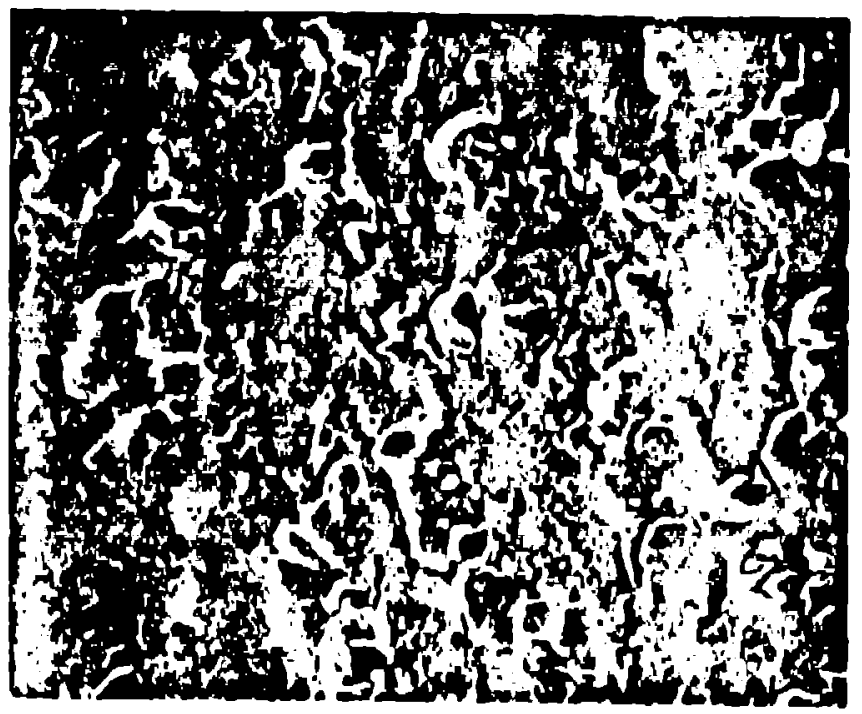

b $\quad 50 \mu \mathrm{m}$

68 dynes/cm

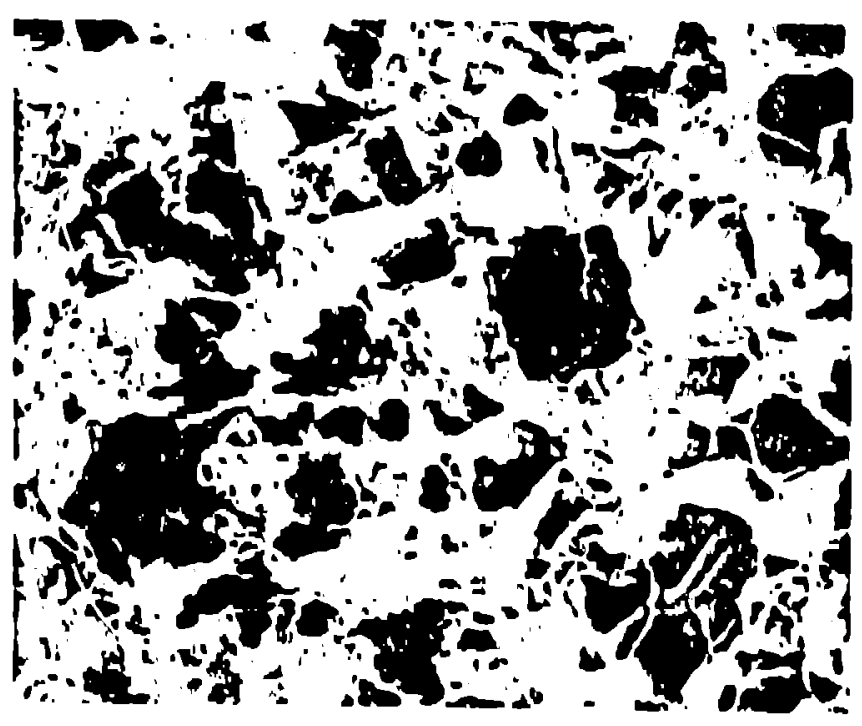

d

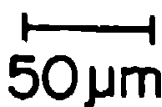

27 dynes/cm 


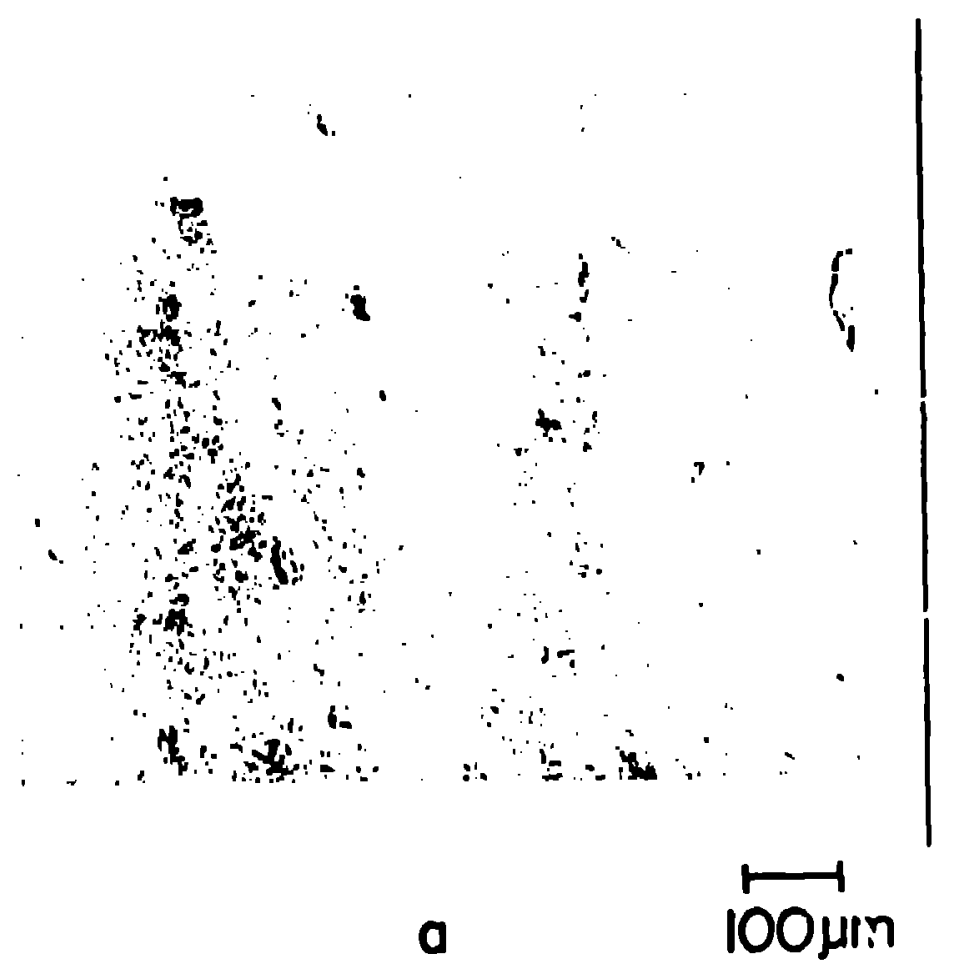

45 dynes/cm

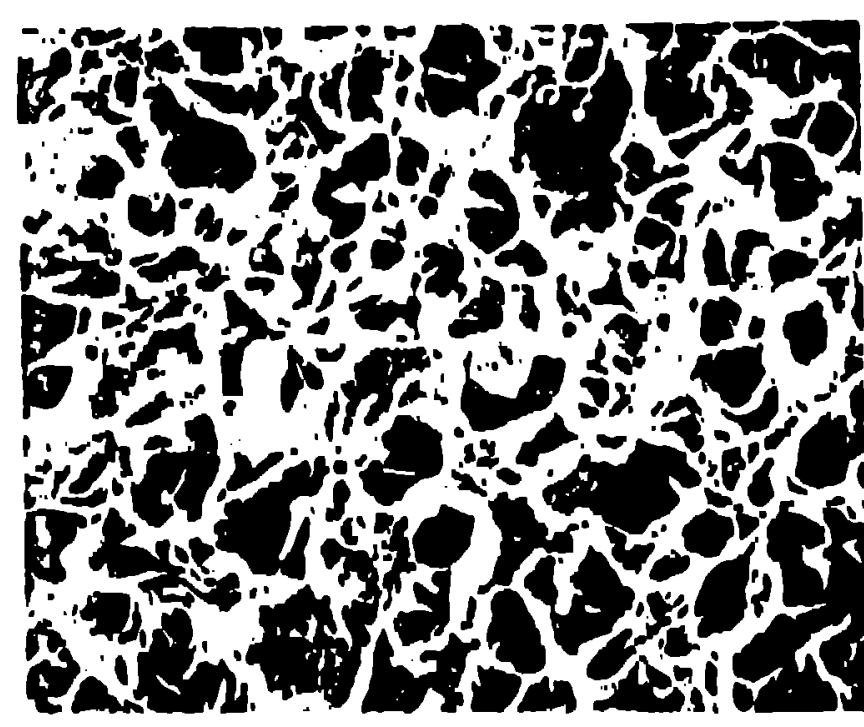

b

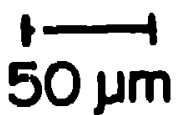

28 dynes/cm 

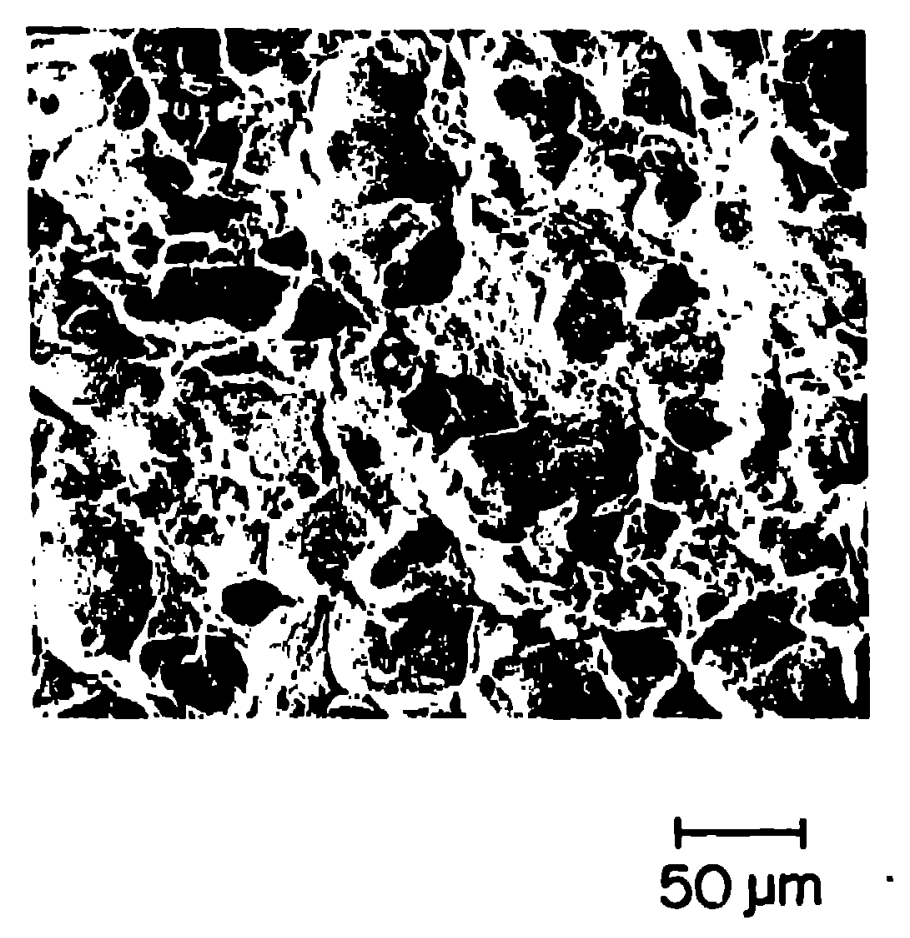



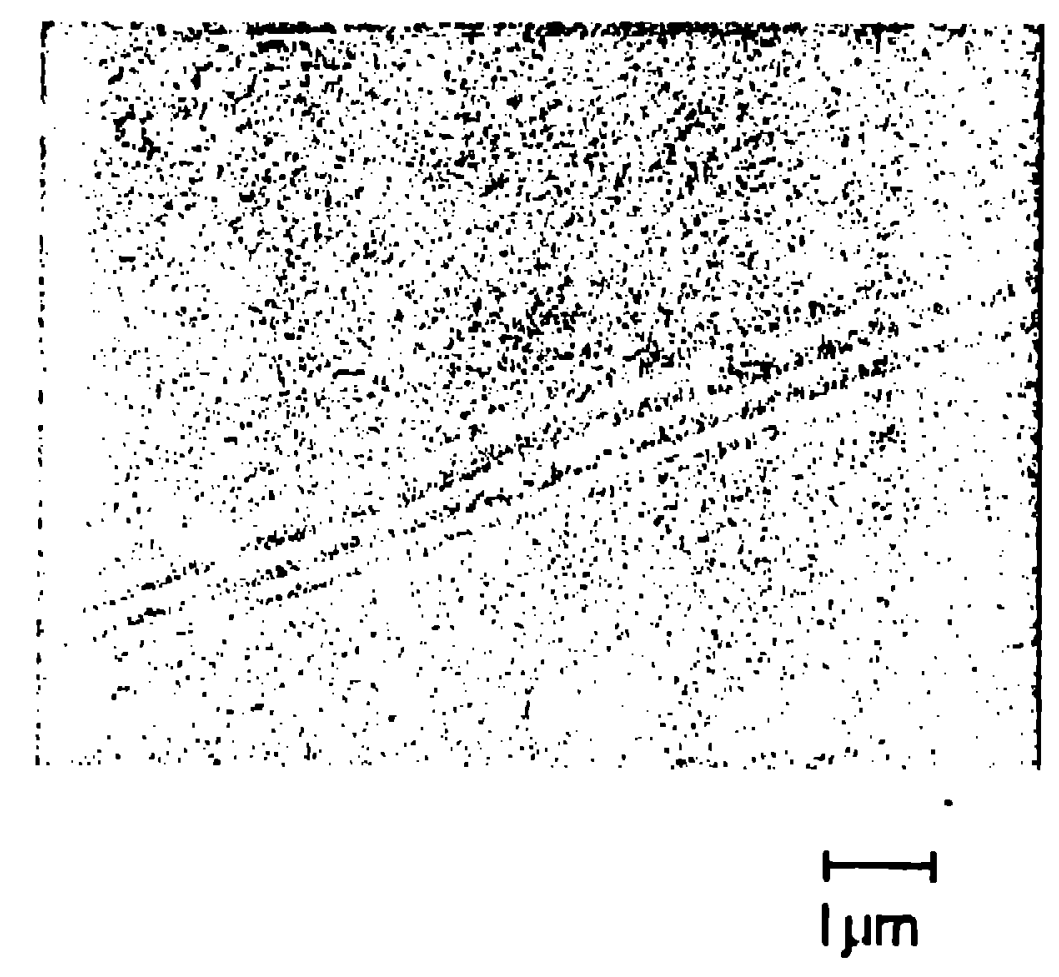

